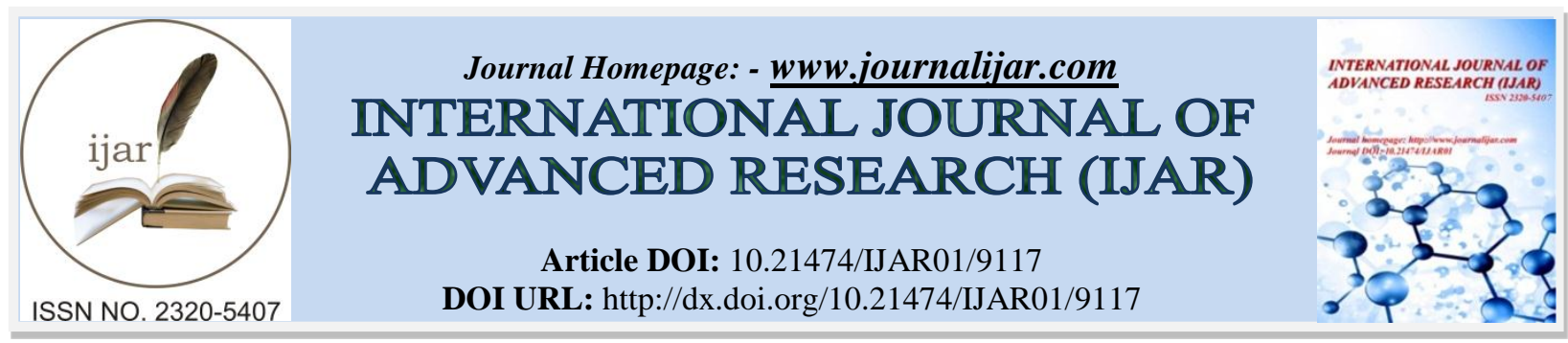

RESEARCH ARTICLE

\title{
SPACE BORNE TECHNIQUE TO IDENTIFY THE RELATIONSHIP BETWEEN VEGETATION COVER AND URBANIZATION IN THE CITY OF COLOMBO.
}

\author{
Saseeka Wijesekera ${ }^{1}$, Sampath Arunashantha ${ }^{2}$, Mangala Jayarathne ${ }^{3}$ \\ Department of Geography, University of Kelaniya, Sri Lanka ${ }^{123}$.
}

\section{Manuscript Info}

Manuscript History

Received: 22 March 2019

Final Accepted: 24 April 2019

Published: May 2019

Key words:-

Urbanization, Vegetation coverage,

Remote Sensing, UI, NDVI.

\section{Abstract}

Urban vegetation coverage can be considered as one of the indicators that can be used to identify, the process of urbanization. Most of the time with rapid urbanization, vegetation coverage in a city tend to decrease. Hence, it is explicitly visible that the social background, building density and related factors to the urbanization process, have a high relationship with minimizing city vegetation coverage. There are many techniques that can be used to identify the relationship between the process of urbanization and vegetation coverage. Space borne (Remote Sensing (RS) technique) is one of the tools to identify such kind of phenomena. As the main commercial hub in the island, the city of Colombo has expanded as an agglomeration and also population density is increasing rapidly. Massive constructions have also covered major parts of the city, rapidly. In the past years, vegetation coverage minimizes with these processes. Considering all these facts, this study has attempted to identify the relationship between vegetation coverage and urbanization in the city of Colombo with the help of RS techniques. Hence, to identify the relationship between vegetation cover and urbanization, Landsat 8 OLI TIRS (2014) satellite images were used to construct Normalize Difference Vegetation Index (NDVI) and Urban Index (UI) to fulfill the study aim. The results indicated that, there is a significant negative relationship between urbanization process and vegetation coverage in the city.

Copy Right, IJAR, 2019,. All rights reserved.

\section{Background:-}

The direct impact of urbanization is rapidly increasing buildup areas. Expansion of urban areas has profound effects on biodiversity and ecosystem functioning at local, regional, and global scales (Zipperer et al.2000). Land use pattern associated with urbanization process leads to modifications of surface microclimatic and hydrological conditions, including the formation of urban heat islands and changes in surface runoff pattern (Hass, 2013).

The vegetation coverage in a city plays a major role in providing an environment for recreation for the inhabitants. These vegetation areas are highly threatened by the transformed urban land use due to increasing pressure on land in most of the cities (Wijesekera \& Manawadu, 2009). The citties' environment, sub urban areas, and towns, rely on vegetation to provide ecosystem functions such as air filtering, temperature amelioration, and water storage, filtration and drainage (Bolund \& Hunhammar1999). When considering the vegetation coverage in city areas, it has a societal value in defining nature for millions of dwellers living in cities sustaining community health and well- 
being (Ulrich 1984; Kuo \& Sullivan 2001; Fuller et al. 2007), as well as frequently contributing to the conservation estate by associate unique biodiversity (McDowell et al.1991; Lawson et al.2008).

According to Verma et al., (2009) the modern technology of RS allows us to collect numerous physical data rather easily, with speed and on repetitive basis and together with Geographic Information Systems (GIS) helps to analyze the data spatially, offering possibilities of generating various options (modeling), thereby optimizing the whole planning process. Also, RS data of various spatial, spectral, and temporal resolutions have been used to characterize land use and land cover change associated with urban growth and application of RS can greatly enhance our knowledge of urban ecological processes (Buyantuyev et al; 2007). Most of the researchers have investigated, the current progresses in RS and GIS having remarkable enhancement about the availability of high-resolution spatial and attribute data for examining the relationship between buildup areas and vegetation structure in a city.

The NDVI is effective in predicting photosynthetic activity, because this vegetation index includes both near infrared and red part of the EMR (Govaerts \& Verhulst, 2010). Green leaves usually have low reflectance in the blue and red portions of the spectrum because of chlorophyll absorption, with a slightly higher reflectance in the green, so plants appear green to our eyes. Near infrared radiant energy is strongly reflected from the plant surface and the amount of this reflectance is determined by the properties of the leaf tissues: their cellular structure and the air-cell wall-protoplasm-chloroplast interfaces (Kumar and Silva, 1973). So this study used NDVI to extract the vegetation coverage through the Landsat satellite imagery.

Mapping city built-up areas using moderate resolution RS data such as Landsat TM/ETM+ data is complex, because urban areas contain manmade and natural features like vegetation, water body, bare land etc. (Sinha et al., 2016). Landsat 8 OLI TIRS, olso has the same magnificient capacity of capturing city build-up areas as moderate resolution RS data. These urban regions frequently show heterogeneous spectral characteristics and significant spectral confusion between land cover classes and as a result reduce mapping accuracy (do). UI is one of the methods to identify city buildup areas using satellite imageries. RS can be used to obtain a description of building density with a spectral transformation called UI (Kawamura et al., 1997). It is assumed that high pixel value indicates built-up area intensively.

There are many researches have done, using both physical and human aspect to reveal some important matters in urbanization process of the city of Colombo using space born techniques. But the comparison of UI and NDVI in RS is limited to the city of Colombo. Hence considering above facts, this study attempts to identify the relationship between the vegetation cover and the degree of urbanization in the Colombo city area. Using UI and NDVI this has been done accordingly with the help of Landsat 8 OLI TIRS Imagery 2014.

\section{Aim of the study:-}

Identify the relationship between vegetation coverage and urbanization in the city of Colombo, using space borne techniques (Special reference to Colombo city Municiple Wards).

\section{Methodology:-}

\section{Study area}

As the main commercial hub in Sri Lanka, the city of Colombo plays a vital role of rapid urbanization in the country. According to the WGS 1984 coordinate system, Colombo city's absolute situation is expanded in between $6^{0} 46^{\prime}$ to $6^{0} 58^{\prime}$ North Latitude and in between nearly $79^{\circ} 00^{\prime}$ to $79^{0} 53^{\prime}$ East Longitude (Figure 01 ).

The city, consists of 47 Municipal Wards (Figure 01and Table 01). Some of these Wards have a high population density while others show comparatively low population density. Also the building density and urbanization process also varies within the Wards. Nearing to the Colombo city harbor area, most of the sky scrapers can be seen. Water bodies like Beira Lake provides cooler environment to the surrounding community within the city. There are a few vegetated areas like Viharamahadevi Public Park, some newly constructed small public park lots, are contributing to make a cooler environment within the city. But this vegetation coverage does not provide sufficient safer and cooler background to avoid the stressful environment generated through traffic congestion, buildings, constructions etc. Considering all these facts, this study has selected the city of Colombo as the study area. 


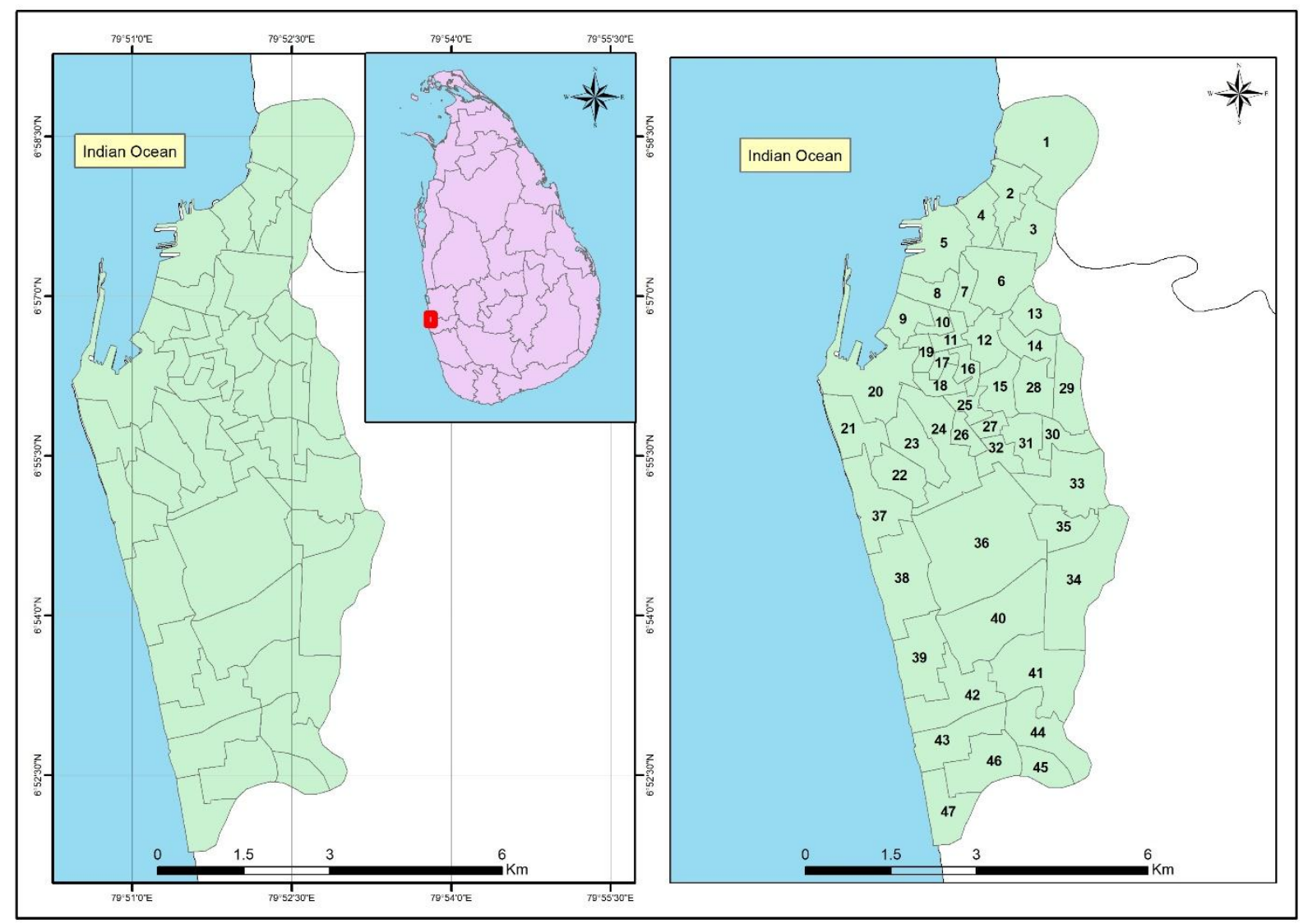

Figure 01: The city of Colombo and Municipal Wards

\begin{tabular}{|l|l|}
\hline Wards ID & Name of the Ward \\
\hline 01 & Mattakkuliya \\
\hline 02 & Modara \\
\hline 03 & Mahawatta \\
\hline 04 & Aluth Mawatha \\
\hline 05 & Lunu Pokuna \\
\hline 06 & Bloomandal \\
\hline 07 & Kotahena East \\
\hline 08 & Kotahena West \\
\hline 09 & Kochchikade North \\
\hline 10 & Ginthupitiya \\
\hline 11 & Masangas Veediya \\
\hline 12 & New Bazaar \\
\hline 13 & Grandpass North \\
\hline 14 & Grandpass South \\
\hline 15 & Maligawatta West \\
\hline 16 & Aluthkade East \\
\hline 17 & Aluthkade West \\
\hline 18 & Keselwatta \\
\hline 19 & Kochchikade South \\
\hline 20 & Fort \\
\hline 21 & Slave Island \\
\hline 22 & Wekanda \\
\hline 23 & Hunupityia \\
\hline
\end{tabular}




\begin{tabular}{|l|l|}
\hline 24 & Suduwella \\
\hline 25 & Panchikawatta \\
\hline 26 & Maradana \\
\hline 27 & Maligawatta West \\
\hline 28 & Maligawatta East \\
\hline 29 & Dematagoda \\
\hline 30 & Wanathamulla \\
\hline 31 & Kuppiyawatta East \\
\hline 32 & Kuppiyawatta West \\
\hline 33 & Borella North \\
\hline 34 & Narahenpita \\
\hline 35 & Borella South \\
\hline 36 & Cinnamon Garden \\
\hline 37 & Kollupitiya \\
\hline 38 & Bambalapitiya \\
\hline 39 & Milagiriya \\
\hline 40 & Thimbirigasyaya \\
\hline 41 & Kirula \\
\hline 42 & Havelock Town \\
\hline 43 & Wellawatta \\
\hline 44 & Kirulapone \\
\hline 45 & Pamankada East \\
\hline 46 & Pamankada West \\
\hline 47 & Wellawatta South \\
\hline
\end{tabular}

Table 01: Name of Wards

\section{Data Collection}

This study depends on the space borne techniques. Therefore the necessary data, Landsat 8 OLI TIRS images on June 2014 were obtained from the website of United State Geological Survey (USGS). It inherits 30m X 30m resolution. The selected Landsat imagery does not cover with cloud and that was an advantage to select for the study.

\begin{tabular}{|l|l|l|}
\hline Bands & Wave length & Resolution \\
\hline Band 1 - Coastal aerosol & $0.43-0.45$ & 30 \\
\hline Band 2 - Blue & $0.45-0.51$ & 30 \\
\hline Band 3 - Green & $0.53-0.59$ & 30 \\
\hline Band 4 - Red & $0.64-0.67$ & 30 \\
\hline Band 5 - Near Infrared (NIR) & $0.85-0.88$ & 30 \\
\hline Band 6 - Short Wave Infrared (SWIR) 1 & $1.57-1.65$ & 30 \\
\hline Band 7 - Short Wave Infrared (SWIR) 2 & $2.11-2.29$ & 30 \\
\hline Band 8 - Panchromatic & $0.50-0.68$ & 15 \\
\hline Band 9 - Cirrus & $1.36-1.38$ & 30 \\
\hline Band 10 - TIRS 1 & $10.60-11.19$ & $100^{*}(30)$ \\
\hline Band 11 - TIRS 2 & $11.5-12.51$ & $100^{*}(30)$ \\
\hline
\end{tabular}

Table 02: Specifications of Landsat 8 OLI TIRS Imagery 


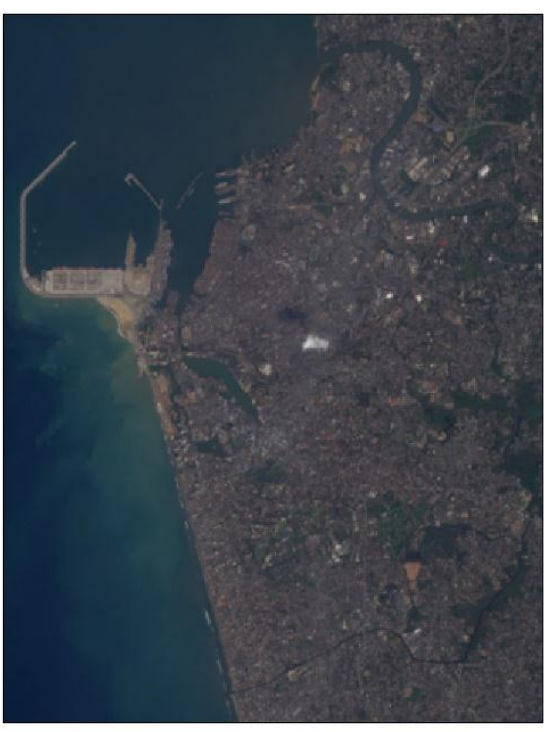

Figure 02: The city of Colombo, Landsat imagery 2014 June

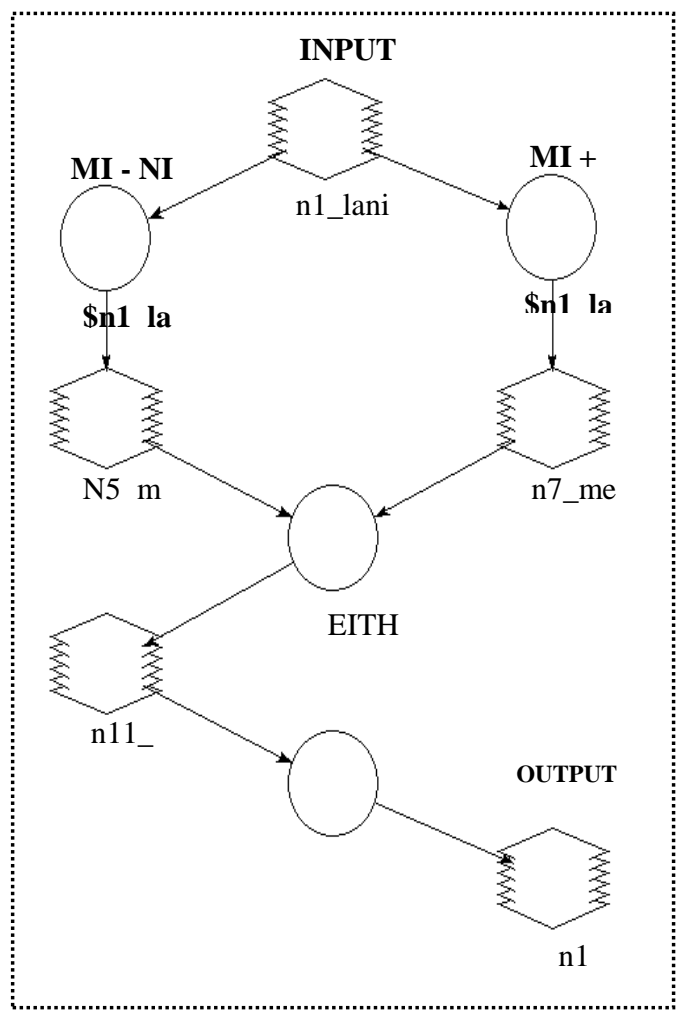

Figure 03: Model of UI

Source $\quad$ : Erdas 10.1

\section{Methods}

It has identified both urbanization process and the vegetation coverage in the city. Erdas Imagine 10.1, RS software was used to generate grid base maps for urbanization and vegetation coverage in the city and ArcGIS 10.1 software were used to construct the pixel base Regression Analysis.

\section{Constructing Urban Index (UI)}

Landsat 8 OLI TIRS satellite data were used to construct the UI. This index depends on the Band 5 (Near Infrared NI) and Band 7 (SWIR 2) that associated with Landsat 8 OLI TIRS data. UI values are varying 49 to 119. When the value reaching 119 it indicates high buildup density.

Below mentioned formula was used to generate the UI.

\section{Formula for UI}

$$
\boldsymbol{U} \boldsymbol{I}=\left(\frac{\boldsymbol{M I}-\boldsymbol{N I}}{\boldsymbol{M I}+\boldsymbol{N} \boldsymbol{I}}+1\right) * 100 \text { (Kawamura et al., 1997) }
$$

The constructed UI, a model was created using Erdas Imagine 10.1 software (Figure 03).

\section{Constructing Normalize Difference Vegetation Index (NDVI)}

NDVI is a calculation of a simple formula consuming two satellite bands. This index is related to identify vegetation coverage and vegetation reflect. Healthy vegetation reflects very well in the near infrared part of the spectrum. Green leaves have a reflectance of 20 percent or less in the 0.5 to 0.7 micron range (green to red) and about 60 percent in the 0.7 to 1.3 micron range (Near Infrared). The visible channel gives some degree of atmospheric correction. The value is then normalized to the range $-1<=\mathrm{NDVI}<=1$ to partially account for differences in illumination and surface slope (Kidwell, 1994).

In RS, NDVI was used to identify the vegetation coverage in a certain area. This study produced NDVI with the help of Landsat 8 OLI TIRS data. To generate NDVI, used band 5 (Near Infrared - NI) and band 4 (Visible Red - R) that are available on Landsat 8 OLI TIRS data. 


\section{Formula for NDVI}

$$
\mathrm{NDVI}=\left(\frac{\mathrm{NI}-\mathrm{R}}{\mathrm{NI}+\mathrm{R}}\right)
$$

Regression analysis is one of the major statistical methods which can be used to show the relationship between two or more considerable variables. Hence to present the relationship between NDVI and UI, least square regression analysis was calculated. NDVI was taken as the independent variables and UI has been chosen as the dependent variable. This regression calculation carried out according to the Municipal Wards of city of Colombo (Figure 01). Apart from pixel distribution calculation, using the function of "Zonal Statistics as a Table" available in ArcGIS 10.1 software link to calculate the regression analysis. This function provides mean values of NDVI and UI according to Municipal Wards in city of Colombo.

\section{Results:-}

As mentioned in methodology when considering the generated grid themes for UI, it shows a remarkable relationship with NDVI (Figure 04). In reality, the highly populated areas like Ginthupitiya, Maradana, Kochchikade, Maligawatta East and West, Grandpass North, Aluthkade East Wards are being showed high UI values. These areas are having less NDVI values (Table 03). Areas like Cinnamon Gardens, Thimbirigasyaya and Narahenpita Wards are enriched with good vegetation coverage. Hence NDVI values for these Wards show high values. All the NDVI pixel values for Colombo city was varied from 0.05 to 0.2 . It is visible, the City has considerable vegetation cover. But when considering UI values, these values were varied from 49 to 119 . It says good urbanization.

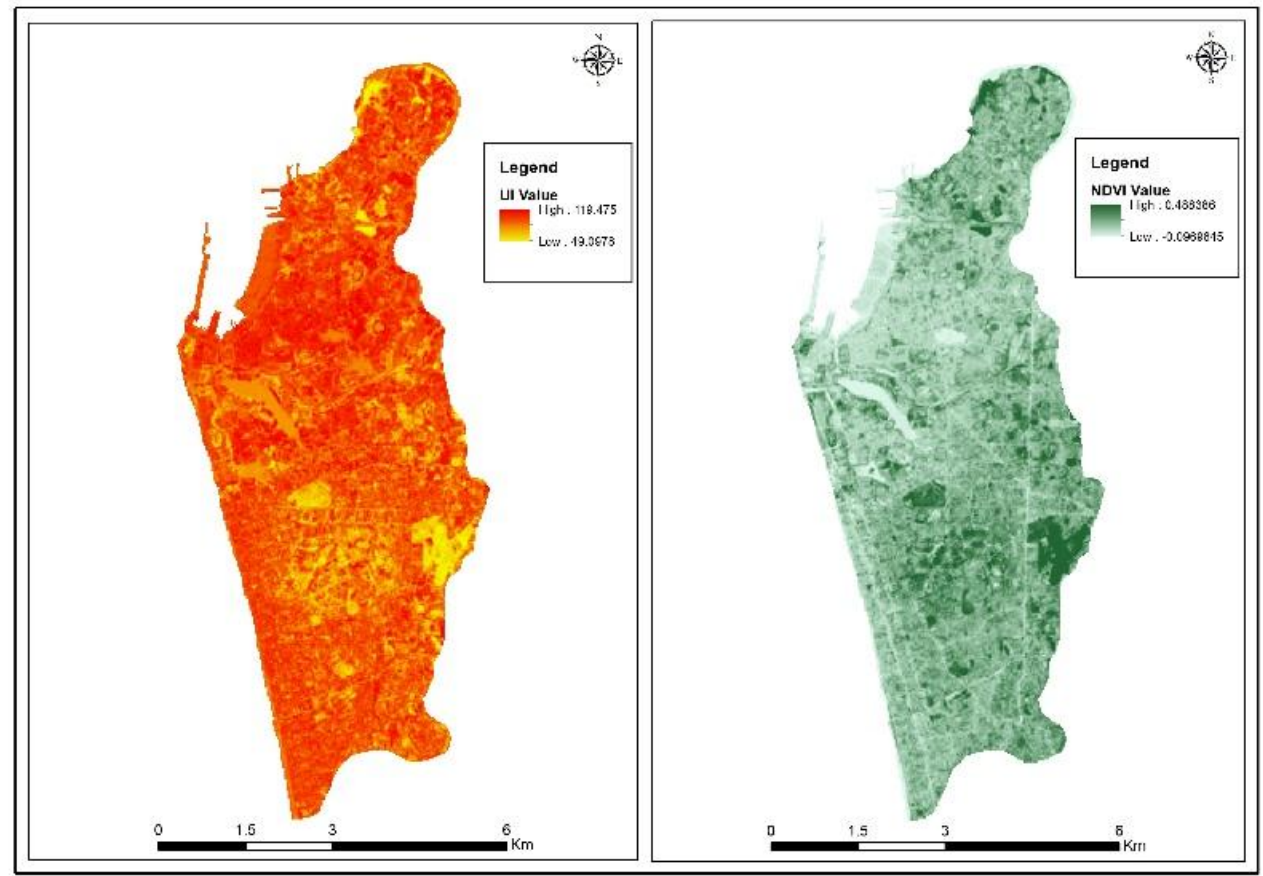

Figure 04: UI and NDVI results of Municipal Council of Colombo

Eg: When considering Ward no 16, that Ward has UI value 97.01 and NDVI value 0.056. Within this situation, we can say that this Ward has less vegetation cover and lots of construction. 


\begin{tabular}{|l|l|l|}
\hline Ward ID & \multicolumn{1}{|c|}{ NDVI } & \multicolumn{1}{|c|}{ UI } \\
\hline 1 & 0.143544 & 89.9656 \\
\hline 2 & 0.141445 & 93.06733 \\
\hline 3 & 0.142716 & 91.19878 \\
\hline 4 & 0.165855 & 89.65855 \\
\hline 5 & 0.096216 & 91.57361 \\
\hline 6 & 0.136841 & 92.11288 \\
\hline 7 & 0.117919 & 94.58343 \\
\hline 8 & 0.091342 & 93.66342 \\
\hline 9 & 0.052655 & 94.33286 \\
\hline 10 & 0.088869 & 98.72836 \\
\hline 11 & 0.094746 & 97.5545 \\
\hline 12 & 0.09043 & 98.46222 \\
\hline 13 & 0.100709 & 95.23898 \\
\hline 14 & 0.115124 & 95.36924 \\
\hline 15 & 0.109783 & 92.19255 \\
\hline 16 & 0.055527 & 97.01878 \\
\hline 17 & 0.076166 & 101.5706 \\
\hline 18 & 0.118291 & 94.34682 \\
\hline 19 & 0.075991 & 99.99392 \\
\hline 20 & 0.0631 & 94.98293 \\
\hline 21 & 0.107204 & 89.1986 \\
\hline 22 & 0.114495 & 94.35163 \\
\hline 23 & 0.097393 & 87.46957 \\
\hline & & \\
\hline
\end{tabular}

\begin{tabular}{|l|l|l|}
\hline Ward ID & \multicolumn{1}{|c|}{ NDVI } & \multicolumn{1}{|c|}{ UI } \\
\hline 24 & 0.118029 & 92.17987 \\
\hline 25 & 0.101473 & 95.27806 \\
\hline 26 & 0.117101 & 93.7925 \\
\hline 27 & 0.116615 & 93.97371 \\
\hline 28 & 0.140932 & 89.87939 \\
\hline 29 & 0.134856 & 93.4575 \\
\hline 30 & 0.179814 & 88.23779 \\
\hline 31 & 0.164895 & 90.68418 \\
\hline 32 & 0.13656 & 94.01706 \\
\hline 33 & 0.183427 & 88.91294 \\
\hline 34 & 0.23216 & 81.91618 \\
\hline 35 & 0.14472 & 91.53904 \\
\hline 36 & 0.185779 & 86.28326 \\
\hline 37 & 0.107462 & 89.16766 \\
\hline 38 & 0.12629 & 91.88191 \\
\hline 39 & 0.122822 & 92.60069 \\
\hline 40 & 0.196806 & 84.73024 \\
\hline 41 & 0.165743 & 89.79179 \\
\hline 42 & 0.150194 & 90.74107 \\
\hline 43 & 0.137932 & 91.15311 \\
\hline 44 & 0.168713 & 90.14808 \\
\hline 45 & 0.169322 & 89.95531 \\
\hline 46 & 0.134247 & 93.07307 \\
\hline 47 & 0.113858 & 92.83152 \\
\hline & & \\
\hline
\end{tabular}

Table 03: Mean Pixel values of UI, NDVI

Source: Generated through ArcGIS 10.1 Zonal Statistics tool

These pixel values of UI and NDVI in Wards showed a remarkable relationship. The areas having high UI values, was carried minimum NDVI values. Figure 05 shows the pixel distribution of each variables in each Wards. 


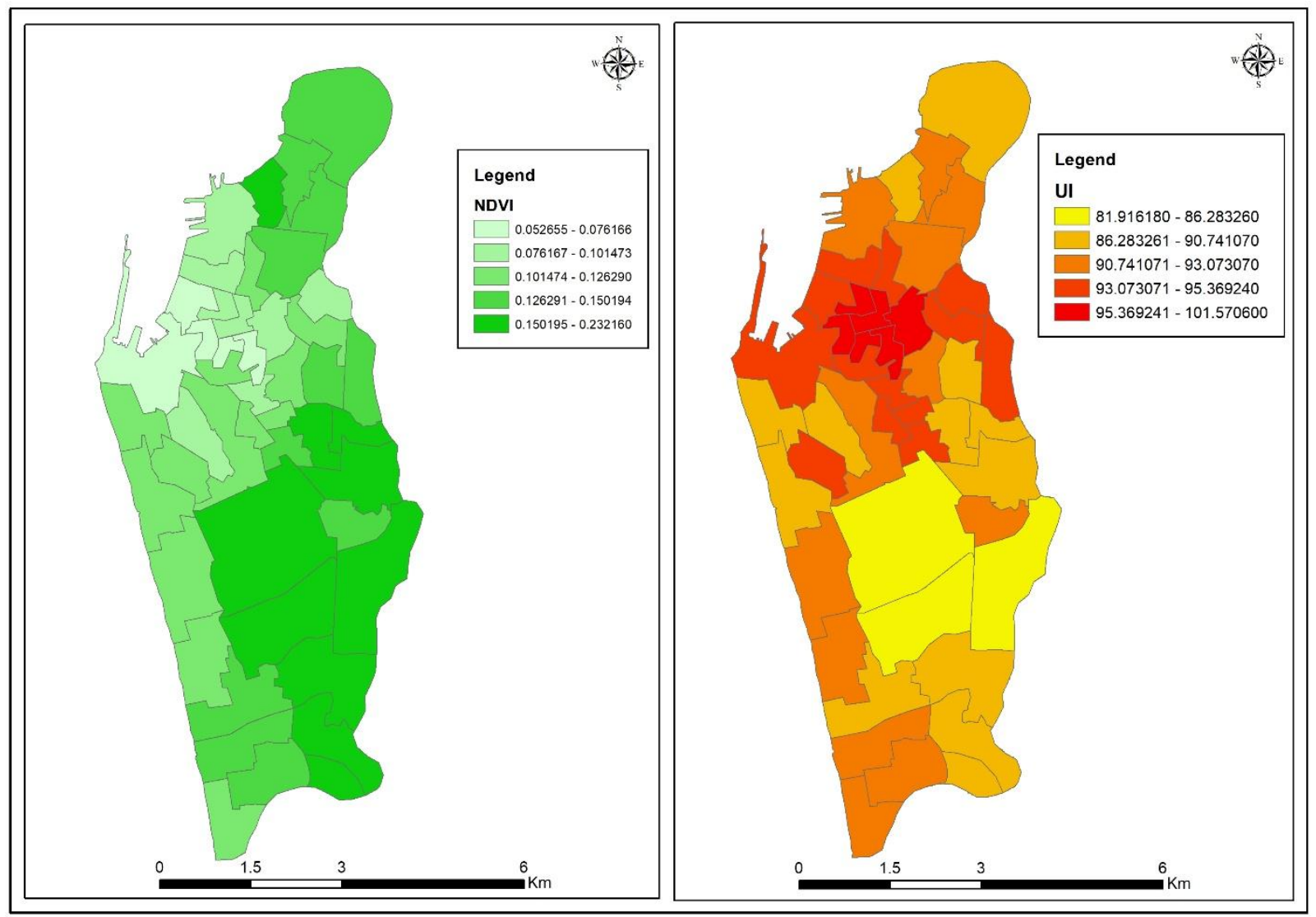

Figure 05: Pixel values for Municipal Wards

When paying attention to the pixel values of the City Wards, it is highly visible that the City Wards where, NDVI value is high, the UI is lower minimum. When it comes to the UI high areas NDVI is minimum. For an example, the City Wards of 36 and 40 (Cinnamon Gardens and Thimbirigasyaya) shows high NDVI values compared to the other City Wards. Especially, Thimbirigasyaya Ward shows the lowest UI values among the other Wards of the city. The specialty of this area is that this area is not covered with high construction of buildings. Also bears a low population density than other regions and tend to maintain vegetation coverage. Also Cinnamon Gardens inherits the Viharamahadevi Public Park with good vegetation coverage.

When, the middle part of the city is compared, these areas carry a high population density. Also high density of buildings can be seen, because of the population concentration. These areas are situated near the Colombo harbor and most of the industrial buildings can be seen there. Hence, the UI values are high in this area and NDVI is low. Figures 06 and 07 show the difference of vegetation coverage in Viharamahadevi Public Park area which is situated in the middle part of the city and Grandpass area nearing to the Colombo Harbor. 

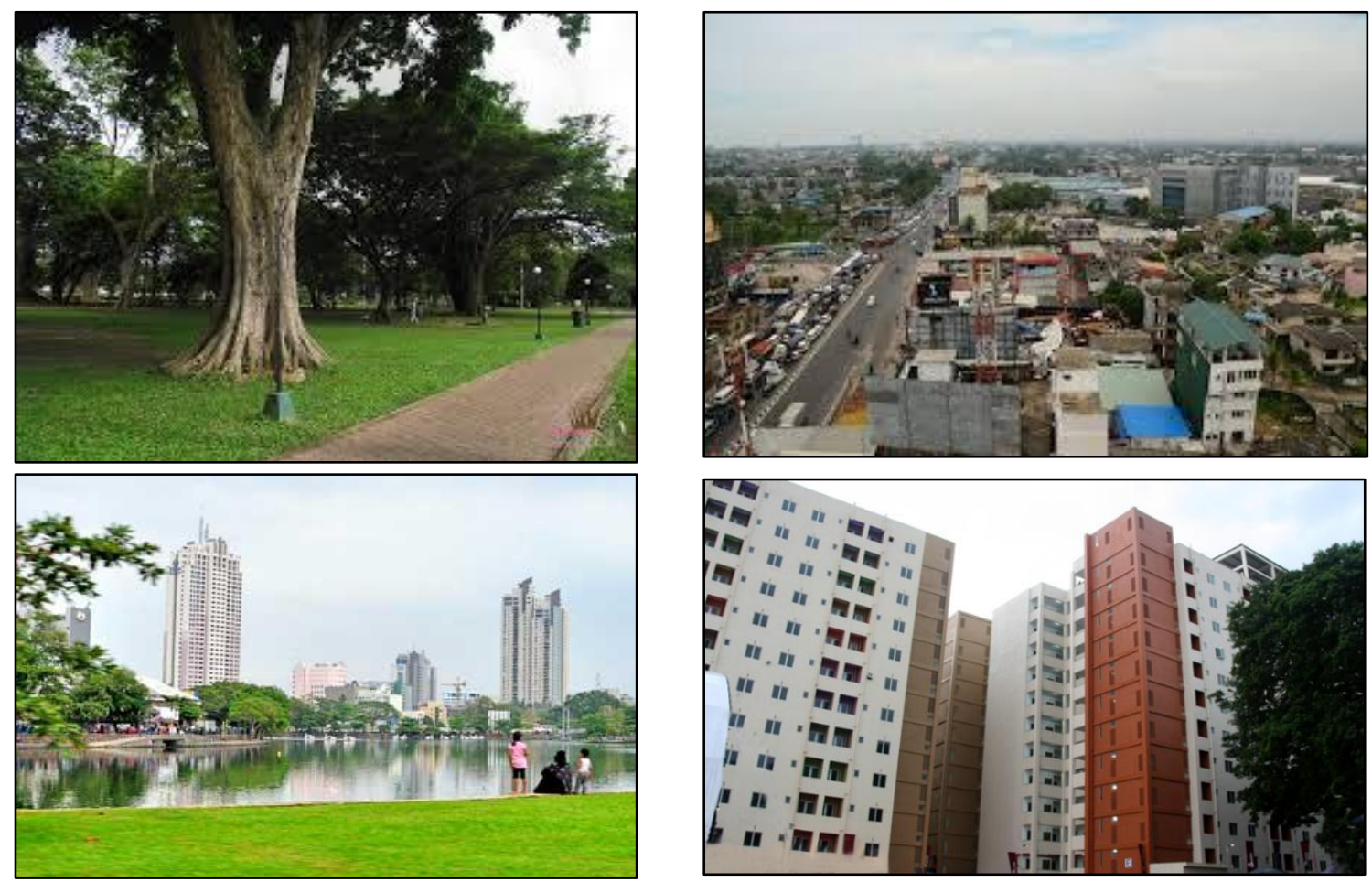

Figure 06: Viharamahadevi Public Park and Diyath Uyana area

Figure 07: Grandpass area and

Mihindusenpura flats in

Dematagoda

When considering the relationship of pixel distribution in Wards, attention was paid to get a well distributed pixels magnificently. All the NDVI values of City Wards, show their DN values towards 0.05 and above. It means, the city vegetation coverage is moderate. Also, UI values in all City Wards, DN values are above 81 (Table 03). To identify the relationship in-between pixel values of NDVI and UI simple regression analysis method was used. In this situation, the study investigated how the urbanization process effects the vegetation coverage.

According to the generated scatter plot diagram shows negative relationship between NDVI and UI (Figure 08). To prove that, linear squared regression line were generated and plot on the scatter plot. The NDVI and UI regression line parameters show $\hat{\mathbf{Y}}=\mathbf{1 0 2 . 3 3}-\mathbf{7 8 . 4 4 8} \mathbf{X}$ (NDVI). When UI is 0, NDVI is -78.448 . When increasing NDVI by one unit, UI will decrease by 102.33 units as an average. Adjusted $\mathrm{R}^{2}$ is 0.6181 . It means $61 \%$ of the variation of UI can be explained by the NDVI. Liner correlation coefficient is -0.78 . It means there is a high negative linear relationship between NDVI and UI. 


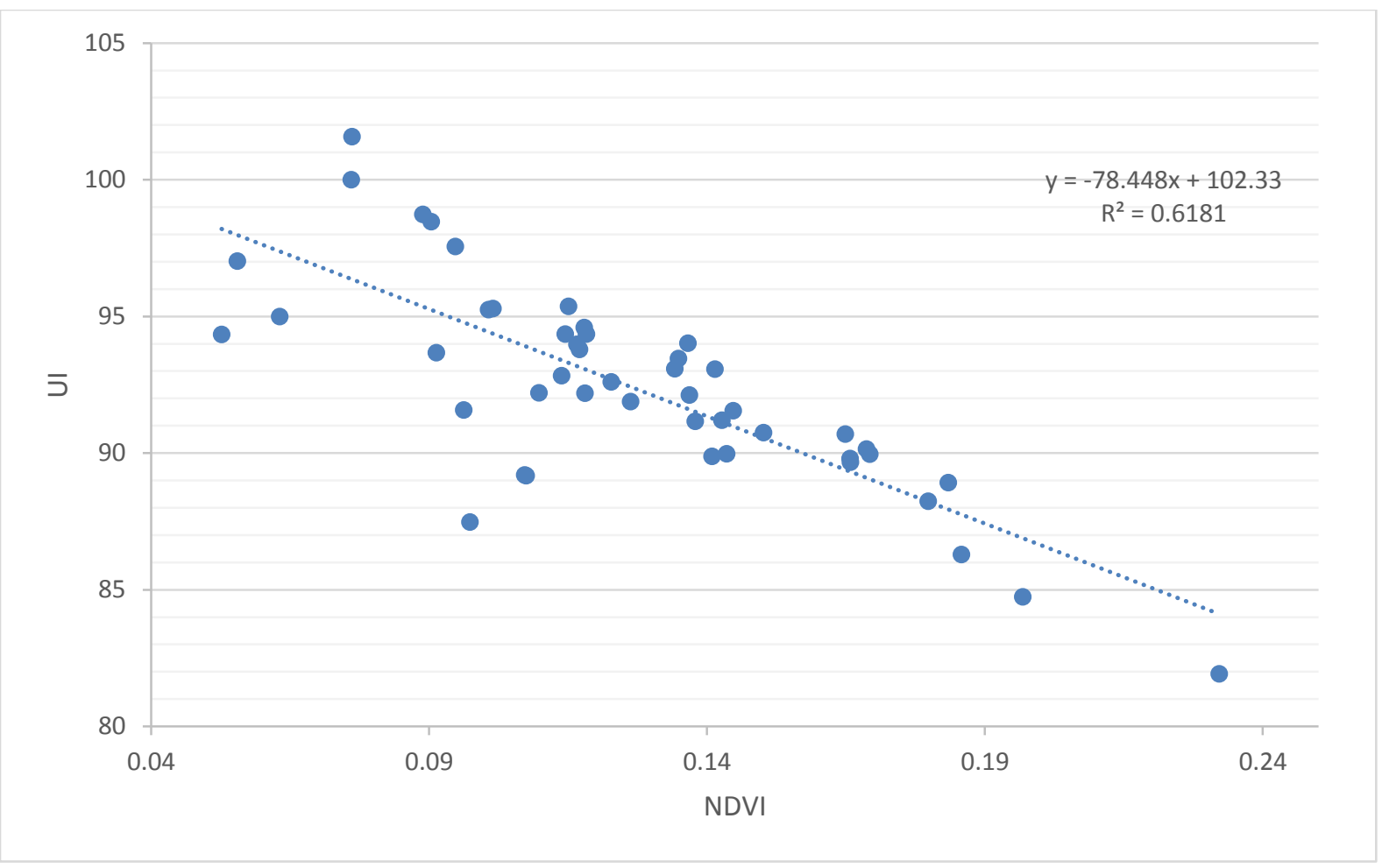

Figure 08: Relationship between NDVI \& UI

Conclusion:-

It has proven that the city of Colombo has a limited vegetation cover. This vegetation coverage vanished with the city development. When focusing UI, most of the DN values concentrated towards North Western part of the City, where the commercial hub situated. Harbor, container yards, services centers, main transportation centers like main bus stand and railway station tend to minimize vegetation in the area. Highest vegetation of the city visible in eastern part of the City, because of the small marshy lands. Also parks like Viharamahadevi Park provides cooler environment to the city. Further, with the city development, the government implemented some environmental programs to increase vegetation coverage.

This study reveals that, space borne techniques are advanced techniques to identify the relationships in environmental studies.

\section{Reference:-}

1. Bolund, P. \& Hunhammar, S. (1999). Ecosystem services in urban areas. Ecological Economics, 29, 293 -301.

2. Buyantuyev, A., Wu, J. \& Gries, C. (2007). Estimating vegetation cover in an urban environment based on Landsat ETM + imagery: A case study in Phoenix, USA. International Journal of Remote Sensing, Vol. 28, No. 2, 269-291, ISSN 0143-1161 print/ISSN 1366-5901 online

3. Fuller, R.A., Irvine, K.N., Devine-Wright, P., Warren, P.H. \& Gaston, K.J. (2007) Psychological benefits of green-space increase with biodiversity. Biology Letters, 3, 390-394

4. Hass, J. (2013). Remote Sensing of Urbanization and Environmental Impacts, Licentiate Thesis, Architecture and the built Environment, Royal Institute of Technology (KTH) ISSN 1653-6126

5. Govaerts B \& Verhulst N (2010). The normalized difference vegetation index (NDVI) Green Seeker TM handheld sensor: Toward the integrated evaluation of crop management Part A: Concepts and case studies Mexico, D.F.; CIMMYT.

6. Kawamura, M., Jayamana, S \& Tsujiko, Y. (1997). Comparison of Urbanization and Environmental Condition in Asian Cities using Satellite Remote Sensing Data, Asian Conference on Remote Sensing (ACRS)

7. Kidwell, K., (1994). Global Vegetation Index User's Guide, U.S. Dept. of Commerce, NOAA/ National Environmental Satellite Data and Information Service, National Climatic Data Center, Satellite Data Services Division.

8. Kumar, R., L. Silva. 1973. Light ray tracing through a leaf cross- section. Appl. Optics 12: 2950-2954 
9. Kuo, F.E. \& Sullivan, W.C. (2001). Environment and crime in the inner city -does vegetation reduce crime? Environment and Behavior ,33, 343-367

10. Lawson, D.M., Lamar, C.K. \& Schwartz, M.W. (2008) Quantifying plant population persistence in humandominated landscapes. Conservation Biology, 22, 922-928.

11. McDowell, C.R., Low, A.B. \& McKenzie, B. (1991). Natural remnants and corridors in Greater Cape Town: their role in threatened plant conservation. The Role of Corridors (eds D.A. Saunders \& R.J. Hobbs), pp. 2739. Surrey Beatty and Sons, Chipping Norton, NSW.

12. Sinha P, Verma N K \& Ayele E (2016). Urban Built-up Area Extraction and Change Detection of Adama Municipal Area using Time-Series Landsat Images. International Journal of Advanced Remote Sensing and GIS 2016, Volume 5, Issue 8, pp. 1886-1895, Article ID Tech-649 ISSN 2320 - 0243

13. Ulrich, R.S. (1984). View through a window may influence recovery from surgery. Science, $224,420-421$.

14. Verma, R.K., Kumari, S. \& Tiwary R.K. (2009). Application of remote sensing and gis technique for efficient urban planning in India. Research Gate

(https://www.google.com/search?q=rationale+of+using+remote+sensing+for+identifying+urbanization+and+vegetat ion\&ie=utf-8\&oe=utf-8\&client $=$ firefoxb \& gfe_rd =cr\&ei=_8UJWJ7ENMSL8Qfn5JTYCg)

15. Wijesekera, S. \& Manawadu, L. (2009). The adverse impact of rapid urbanization on the vegetation cover in the Colombo metropolitan region, National Geography Conference (NGC) Sri Lanka.

16. Zipperer W.C., Wu J., Pouyat R.V. \& Pickett, S.T.A., (2000). The application of ecological principles to urban and urbanizing landscapes. Ecological Applications, 10, pp. 685-688. 